\title{
An Analytical Model for Predicting Ground Pressure under a Rigid-Flexible Tracked Vehicle on Soft Ground
}

\author{
Weiwei Liu $\mathbb{D}^{1,2}$ and Kai Cheng $\mathbb{D}^{1}$ \\ ${ }^{1}$ School of Mechanical Science and Engineering, Jilin University, Changchun, China \\ ${ }^{2}$ School of Mechanical Engineering, Beihua University, Jilin City, China \\ Correspondence should be addressed to Kai Cheng; chengkai@jlu.edu.cn
}

Received 29 July 2019; Revised 27 November 2019; Accepted 3 December 2019; Published 22 January 2020

Academic Editor: José António Fonseca de Oliveira Correia

Copyright (C) 2020 Weiwei Liu and Kai Cheng. This is an open access article distributed under the Creative Commons Attribution License, which permits unrestricted use, distribution, and reproduction in any medium, provided the original work is properly cited.

\begin{abstract}
Ground pressure is a significant parameter for the mobility, tractive performance, and soil compaction. In this study, an analytical model for predicting ground pressure distribution under a rigid-flexible tracked vehicle on soft ground was developed. The model considered the primary design parameters of the tracked vehicle, soil characteristics, and soil shear. The ground pressure was not uniform, and its maximum values under the roadwheels were $90.20,103.57$, and $150.14 \mathrm{kPa}$. The ground pressure was inversely proportional to the ratio of the lengths of the flexible track and rigid grouser. An experiment was conducted to verify the analytical model. The maximum error between the measured and simulated results was smaller than $8 \%$, thereby verifying the analytical model.
\end{abstract}

\section{Introduction}

Tracked vehicles have become increasingly popular in various complex terrain and special ground conditions, such as snow land, desert, swamps, jungles, mountains, and lakes, because of their high mobility. Ground pressure, which is the stress distribution in the context of the soil-track interface, is an important parameter for mobility, tractive performance, and soil compaction. Nominal ground pressure, which is obtained by dividing the vehicle weight by the soil-track contact areas, represents the ground pressure under the track on the basis of the uniform distribution. However, ground pressure is not uniform, especially in cases in which the track is flexible. In the past several decades, ground pressure has been investigated by many researchers and is found to be complex due to various factors, such as the number of roadwheels, the diameter of roadwheels, track tension, and soil characteristics. Bekker [1] proposed the pressuresinkage formula by fitting large amounts of experimental data. The vertical deformation of soil under load was assumed similar to soil deformation under a flat plate. The ground pressure under a flat plate was derived using the following equation:

$$
p=\left(\frac{k_{c}}{b}+k_{\varphi}\right) z^{n}
$$

where $p$ is the ground pressure, $b$ is the track width, $z$ is the sinkage, and $k_{c}, k_{\psi}$, and $n$ are the parameters derived from the plate sinkage tests.

Mohr's theory states that materials will fail from a critical combination of normal and shearing stresses. Waldron [2] demonstrated that the Mohr theory was suitable for soil. The relationship between normal and shear stresses in the sliding surface can be described by Mohr's envelope. The envelope is given by the Coulomb formula:

$$
\tau=c+p \tan \varphi
$$


where $\tau$ is the shear stress, $c$ is the soil cohesion, and $\varphi$ is the internal friction angle.

When the track shoe cuts the soil, the soil becomes subjected to compression. As the ground pressure acts on the soil surface, the soil in this area can be considered in a Rankine passive state [3]:

$$
\sigma_{p n}=\gamma_{s} z K_{p y}+p K_{p q}+c K_{p c},
$$

where $\sigma_{p n}$ is the ground pressure acting on the vertical surface of a grouser, $\gamma_{s}$ is the unit weight of soil, and $K_{p y}, K_{p q}$, and $K_{p c}$ are coefficients related to soil strength.

Keller et al. [4-6] obtained the vertical and lateral soil stress pressures under rubber-tracked agricultural machinery via experimental data fitting. The prediction formula considered the vehicle properties, such as the number and diameter of roadwheels, but disregarded the soil characteristics. Moreover, the longitudinal (i.e., the driving direction) and the lateral (i.e., perpendicular to the driving direction) ground pressures were used as the upper stress boundary conditions to simulate the soil stresses. Zhao et al. [7] obtained the longitudinal ground pressure via experimental data fitting under the assumption that the ground pressure under the roadwheels is a quadratic cosine function and others are linear functions considering the number of roadwheels and the ground contact length. They also determined the lateral ground pressure under the assumption that the pressure is a linear function. Sun et al. [8] obtained the sinkage through the experimental data fitting. Then, the corrected model of normal and shear stresses under the flexible track was obtained using the model of Wong.

Garber and Wong $[9,10]$ developed an analytical method for predicting ground pressure under a tracked vehicle in a static condition by considering the vehicle parameters and soil characteristics. They analyzed the effects of initial track tension, track tension, number of roadwheels, diameter of roadwheels, suspension stiffness, and soil characteristics on the ground pressure distribution through an analytical method. Park et al. [11] introduced a mathematical model for predicting soil normal and shear stresses under a flexible tracked vehicle by considering not only the vehicle parameters and soil characteristics but also the repetitive loading. They used a traction test to verify the mathematical model. Li et al. [12] proposed an analytical method for predicting ground pressure under the rigid grouser by utilizing force balance. Yang et al. [13] corrected the model of Li by considering the soil shear and obtained the soil shear rate through the finite element method. They adopted traction experiments to verify the analytical model.

Wong and Huang $[14,15]$ investigated the relationship of ground pressure with initial track tension by using advanced computer simulation models, namely, TPPVTV (Tractive Performance Prediction Model for Tracked Vehicle) and NTVPM (Nepean Tracked Vehicle Performance Model). Meywerk et al. [16] adopted a coupled model of multibody system-finite element method to obtain real-time soil deformation.

The abovementioned research methods of ground pressure are focused on fitting, mathematical analysis, and dynamic analysis, and the research objective is a flexible or rigid track. However, ground pressure has not yet been analyzed under a coupled rigid-flexible track. The rigid-flexible track system is widely used in all-terrain tracked vehicles. The objectives of current study are as follows:

(i) To develop a mathematical model for predicting ground pressure along the longitudinal direction by using the primary design parameters of the tracked vehicle, as well as the soil characteristics and soil shear, and assuming a uniform ground pressure along the lateral direction

(ii) To conduct an experiment that verifies and validates the theoretical model

(iii) To analyze the influence of the lengths of the flexible track and rigid grouser on the ground pressure

\section{Analytical Model}

Flexible track is usually called a rubber track. A rigid track is connected by metal track shoes, and the soil can only have a convex deformation. The studied track system is different from the traditional flexible and rigid tracks; it is a type of rigid-flexible coupled track that consists of a rubber track and metal grousers. This track system can obtain a smaller ground pressure than the rigid track and a longer fatigue life than the flexible track, as shown in Figure 1. When a tracked vehicle drives on soft soil, the ground pressure distribution beneath the track depends on the soiltrack interaction, as shown in Figure 2. The pressuresinkage relationship (equation (1)), Coulomb formula (equation (2)), and Rankine passive state (equation (3)) are considered. Finite element analysis is used to analyze the entire track system. The track system in the context of its contact with the soil is divided into the track segment in contact with a roadwheel and the track segment between the roadwheels.

2.1. Analysis of the Track Segment in Contact with a Roadwheel. The shape of the track segment in contact with a roadwheel is dependent on the roadwheel diameter. Consider an arbitrary element from the track segment in contact with a roadwheel with the number $i$, the radius $r_{i}$, the central angle $\mathrm{d} \theta$, and the length of the track segment $\mathrm{d} l=r_{i} \mathrm{~d} \theta$, as shown in Figure 3. The force and torque equilibrium are represented by equations (4)-(6). where $T_{\alpha i}$ and $T_{\beta i}$ represent the tensions at the entry and exit angles, respectively, $\alpha_{i}$ and $\beta_{i}$ represent the entry and exit angles of the $i$ th roadwheel, respectively, $W_{i}$ represents the vertical load of the $i$ th roadwheel, and $h$ represents the width of the flexible track. 


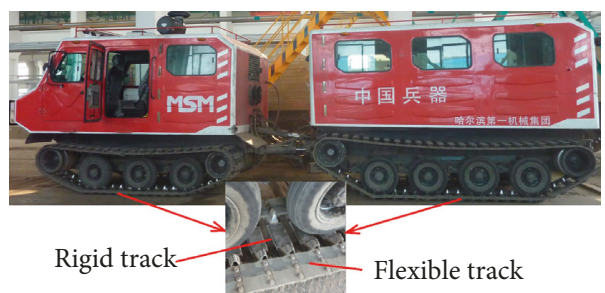

FiguRE 1: Rigid-flexible coupled track.

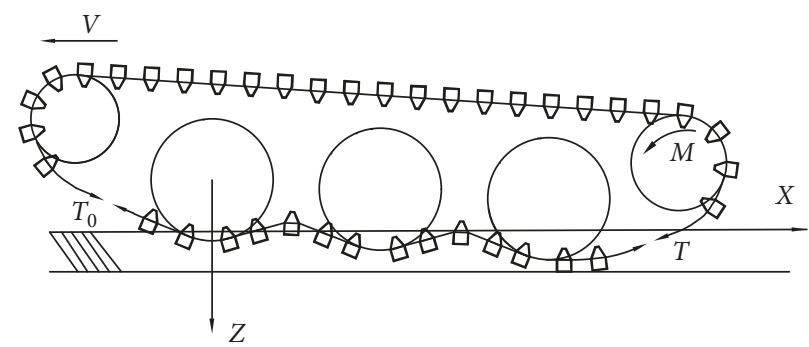

Figure 2: Configuration of a track system in contact with soft ground.

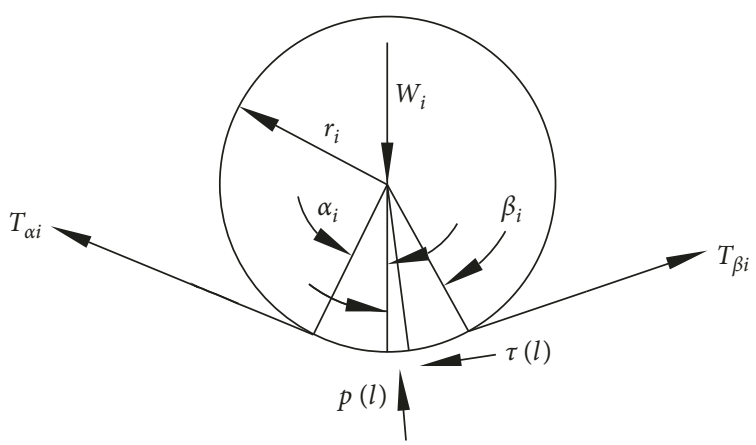

FIGURE 3: Forces acting on the roadwheel in contact with a track segment.

$$
\begin{gathered}
T_{\beta i} \cos \left(\alpha_{i}+\beta_{i}\right)+W_{i} \sin \alpha_{i}=T_{\alpha i}+h \int_{0}^{r_{i}\left(\alpha_{i}+\beta_{i}\right)} p(l) \sin \left(\alpha_{i}+\frac{l}{r_{i}}\right) \mathrm{d} l+h \int_{0}^{r_{i}\left(\alpha_{i}+\beta_{i}\right)}[c+p(l) \tan \varphi] \cos \left(\alpha_{i}+\frac{l}{r_{i}}\right) \mathrm{d} l, \\
T_{\beta i} \sin \left(\alpha_{i}+\beta_{i}\right)+W_{i} \cos \alpha_{i}=h \int_{0}^{r_{i}\left(\alpha_{i}+\beta_{i}\right)} p(l) \cos \left(\alpha_{i}+\frac{l}{r_{i}}\right) \mathrm{d} l+h \int_{0}^{r_{i}\left(\alpha_{i}+\beta_{i}\right)}[c+p(l) \tan \varphi] \sin \left(\alpha_{i}+\frac{l}{r_{i}}\right) \mathrm{d} l \\
T_{\beta i} r_{i}=h r_{i} \int_{0}^{r_{i}\left(\alpha_{i}+\beta_{i}\right)}[c+p(l) \tan \varphi] \mathrm{d} l+T_{\alpha i} r_{i}
\end{gathered}
$$

For the first roadwheel $(i=1), T_{\alpha 1}=T_{0}$ (equation (7)) and $\alpha_{i}=\alpha_{0}$ (the approach angle of the track system). The ground pressure $p(l)$ and the tension at the exit angle $T_{\beta i}$ can be calculated on the basis of equations (4)-(7) and the primary design factors, such as the vehicle weight, the track width, the number and diameter of roadwheels and sprocket, and the torque acting on the sprocket. Then, the vertical load of the first roadwheel $W_{1}$ and shear stress $\tau(l)$ can be obtained.

For the last roadwheel $(i=3), T_{\beta i}=T$ (equation (7) [17]) and $\beta_{i}=\beta$ (the departure angle of the track system). The ground pressure $p(l)$ and the tension at the entry 


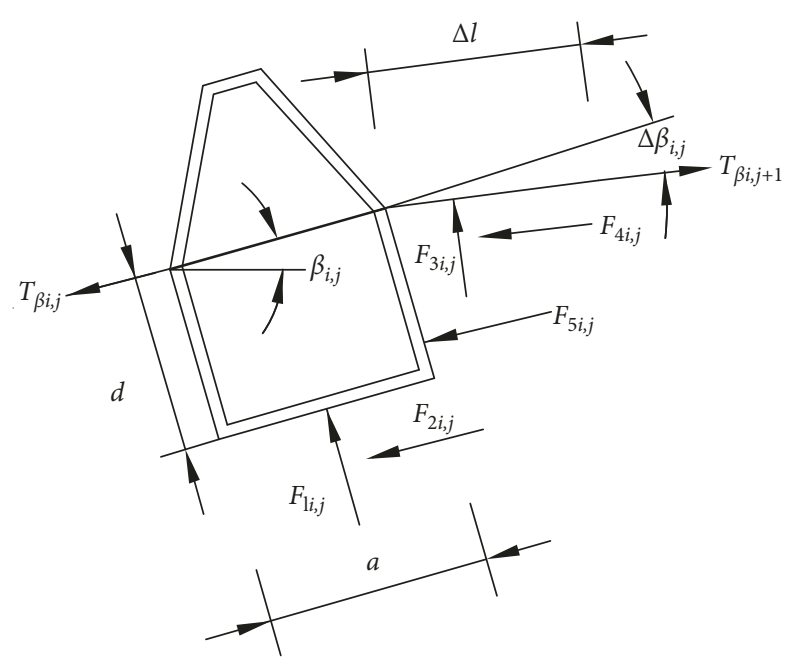

FIGURE 4: Force acting on the track segment between roadwheels.

angle $T_{\alpha i}$ can be calculated on the basis of equations (4-7) and the primary design factors. Then, the vertical weight of the last roadwheel $W_{3}$ and shear stress $\tau(l)$ can be obtained.

$$
\begin{aligned}
T_{0} & =\left(\frac{3}{4} W-\frac{M}{r_{S}}\right), \\
T & =\left(\frac{3}{4} W+\frac{M}{r_{S}}\right),
\end{aligned}
$$

where $M$ is the torque acting on the sprocket, $T_{0}$ is the tension at the approach angle of the track system, $T$ is the tension at the departure angle of the track system, $W$ is the vehicle weight, and $r_{S}$ is the diameter of the sprocket.

2.2. Analysis of the Track Segment between the Roadwheels. The shape of the track segment between the roadwheels is dependent on the interaction between the soil and track. One rigid grouser and one adjacent flexible track element $\Delta l$ are used as the research objects, as shown in Figure 4. The force equilibriums are represented by equations (8) and (9):

$$
\begin{aligned}
T_{\beta i, j+1} \cos \Delta \beta_{i, j}= & T_{\beta i, j}+F_{2 i, j}+F_{5 i, j}+F_{3 i, j} \sin \Delta \beta_{i, j} \\
& +F_{4 i, j} \cos \Delta \beta_{i, j}, \\
T_{\beta i, j+1} \sin \Delta \beta_{i, j}= & F_{1 i, j}+F_{3 i, j} \cos \Delta \beta_{i, j}+F_{4 i, j} \sin \Delta \beta_{i, j},
\end{aligned}
$$

where $T_{\beta i, j}$ and $T_{\beta i, j+1}$ represent the tensions of the $j$ th and $j+1$ th elements in the $i$ th segment, respectively. $\beta_{i, j}$ represents the angle between the rigid grouser and horizontal direction. $\Delta \beta_{i, j}$ represents the angle between the rigid grouser and flexible track element. $F_{1 i, j}$ is the normal force under the rigid grouser (equation (10)). $F_{2 i, j}$ is the tangential force under the rigid grouser (equation (11)). $F_{3 i, j}$ is the normal force under the $j$ th flexible track element (equation (12)). $F_{4 i, j}$ is the tangential force under the $j$ th flexible track element (equation (13)). $F_{5 i, j}$ is the force acting on the vertical surface of the rigid grouser (equation (14)). For the first element $(j=1), T_{\beta i, j}=T_{\beta i}$ and $\beta_{i, j}=\beta_{i}$. For the last element, $T_{\beta i, j}=T_{\alpha i+1}$ and $\beta_{i, j}=\alpha_{i+1}$. Hence, the ground pressure under the track between the roadwheels can be calculated.

$$
F_{1 i, j}=a b p_{1 i, j}
$$

where $a$ represents the length of the rigid grouser.

$$
\begin{aligned}
F_{2 i, j}= & a b p_{2 i, j}=a b\left[c+p_{1 i, j} \tan \varphi\right], \\
F_{3 i, j}= & h \int p_{3 i, j}(l) \mathrm{d} l, \\
F_{4 i, j}= & h \int\left[c+p_{3 i, j}(l) \tan \varphi\right] \mathrm{d} l, \\
F_{5 i, j}= & b \int_{0}^{d} \frac{\left(\gamma_{s} z K_{p y}+c K_{p c}\right) \mathrm{d} z+c d b \sin \beta_{i, j}}{\cos \beta_{i, j}+b \tan \varphi \sin \beta_{i, j}} \\
& \cdot \int_{0}^{d}\left(\gamma_{s} z K_{p y}+c K_{p c}\right) \mathrm{d} z,
\end{aligned}
$$

where $d$ represents the height of the grouser.

For a rigid-flexible tracked vehicle with the number of roadwheels $N$, the number of rigid grouser $R$, and the number of flexible tracks $Q$, when the track segments are in equilibrium conditions, the vertical and horizontal forces of the entire system are satisfied (equations (15)-(16)). Finally, the entire track system can be repeatedly analyzed via equations (1-16). 
TABLE 1: Input data for the analytical model.

\begin{tabular}{|c|c|c|}
\hline Parameters & Values & Units \\
\hline Soil cohesive modulus $\left(k_{c}\right)$ & 10.21 & $\mathrm{kN} / \mathrm{mm}^{n+1}$ \\
\hline Soil frictional modulus $\left(k_{\psi}\right)$ & 300.52 & $\mathrm{kN} / \mathrm{mm}^{n+2}$ \\
\hline Sinkage exponent $(n)$ & 0.53 & - \\
\hline Soil cohesion $(c)$ & $2.10 \times 10^{-3}$ & $\mathrm{~Pa}$ \\
\hline Soil internal friction angle $(\psi)$ & 10 & $0^{\circ}$ \\
\hline Unit weight of soil $\left(\gamma_{s}\right)$ & $7.8 \times 10^{4}$ & $\mathrm{kN} / \mathrm{m}^{3}$ \\
\hline Weight of the track vehicle $(W)$ & 49 & $\mathrm{kN}$ \\
\hline Torque acting on the sprocket $(M)$ & 7.8 & $\mathrm{kN} \cdot \mathrm{m}$ \\
\hline Approach angle of the track system $\left(\alpha_{0}\right)$ & 11 & $\circ$ \\
\hline Departure angle of the track system $(\beta)$ & 9 & $\circ$ \\
\hline Radius of the roadwheels $\left(r_{1}, r_{2}, r_{3}\right)$ & 298 & $\mathrm{~mm}$ \\
\hline Radius of the sprocket $\left(r_{S}\right)$ & 220 & $\mathrm{~mm}$ \\
\hline The grouser width $(b)$ & 440 & $\mathrm{~mm}$ \\
\hline Length of the grouser $(a)$ & 74 & $\mathrm{~mm}$ \\
\hline Height of the grouser $(d)$ & 55 & $\mathrm{~mm}$ \\
\hline Length of the flexible track $(l)$ & 90 & $\mathrm{~mm}$ \\
\hline Flexible track width $(h)$ & 600 & $\mathrm{~mm}$ \\
\hline Number of roadwheel $(N)$ & 3 & - \\
\hline Number of rigid grouser $(R)$ & 15 & - \\
\hline Number of flexible track $(Q)$ & 14 & - \\
\hline
\end{tabular}

$$
\begin{aligned}
T \cos \beta_{N}= & T_{0} \cos \alpha_{1}+\sum_{1}^{N}\left(h \int_{0}^{r_{i}\left(\alpha_{i}+\beta_{i}\right)}[c+p(l) \tan \varphi] \cos \left(\alpha_{i}+\frac{l}{r_{i}}\right) \mathrm{d} l\right)+a b \sum_{1}^{R} \sum_{1}^{N} p_{1 i j} \sin \left(\beta_{i}-\Delta \beta_{i j}\right) \\
+ & a b \sum_{1}^{R} \sum_{1}^{N} p_{1 i j} \sin \left(\beta_{i}-\Delta \beta_{i j}\right)+a b \sum_{1} \sum_{1}^{N}\left[c+p_{1 i j} \tan \varphi\right] \cos \left(\beta_{i}-\Delta \beta_{i j}\right)+h \sum_{1}^{Q} \int_{0}^{l} p_{3 i j}(l) \sin \left(\beta_{i}-\Delta \beta_{i j}\right) \mathrm{d} l \quad(15) \\
+ & h \sum_{1}^{Q} \int_{0}^{l}\left(c+p_{3 i j}(l) \tan \varphi\right) \cos \left(\beta_{i}-\Delta \beta_{i j}\right) \mathrm{d} l+b \sum_{1}^{R} \int_{0}^{d}\left(\gamma_{s} z K_{p y}+c K_{p c}\right) \sin \left(\beta_{i}-\Delta \beta_{i j}\right) \mathrm{d} z, \\
T_{0} \sin \alpha_{1}+T \sin \beta_{N}= & \sum_{1}^{N}\left(h \int_{0}^{r_{i}\left(\alpha_{i}+\beta_{i}\right)} p(l) \cos \left(\alpha_{i}+\frac{l}{r_{i}}\right) \mathrm{d} l\right)+a b \sum_{1}^{R} \sum_{1}^{N} p_{1 i j} \cos \left(\beta_{i}-\Delta \beta_{i j}\right)+a b \sum_{1}^{R} \sum_{1}^{N} p_{1 i j} \cos \left(\beta_{i}-\Delta \beta_{i j}\right) \\
& +a b \sum_{1}^{R} \sum_{1}^{N}\left(c+p_{1 i j} \tan \varphi\right) \sin \left(\beta_{i}-\Delta \beta_{i j}\right)+h \sum_{1}^{Q} \int_{0}^{l} p_{3 i j}(l) \cos \left(\beta_{i}-\Delta \beta_{i j}\right) \mathrm{d} l \\
& +h \sum_{1}^{Q} \int_{0}^{l}\left(c+p_{3 i j}(l) \tan \varphi\right) \sin \left(\beta_{i}-\Delta \beta_{i j}\right) \mathrm{d} l+b \sum_{1}^{R} \int_{0}^{d}\left(\gamma_{s} z K_{p y}+c K_{p c}\right) \cos \left(\beta_{i}-\Delta \beta_{i j}\right) \mathrm{d} z+W .
\end{aligned}
$$

With the front car as an example, on the basis of the analytical model for predicting ground pressure under a rigid-flexible tracked vehicle on soft ground and the input data (Table 1), the ground pressure (Figure 5) can be calculated. Moreover, the soil and vehicle parameters were obtained from Harbin First Machinery Building Group Ltd.

\section{Measurements of Ground Pressure}

The analytical model was verified through the ground pressure test, which was conducted at the test site of Harbin First Machinery Building Group Ltd. The test vehicle with a total weight of $148.90 \mathrm{kN}$ was driven at the speed of $10 \mathrm{~km} / \mathrm{h}$. To measure the ground pressure distribution below the roadwheels, two stress sensors (diameter, $16 \mathrm{~mm}$; height, $6 \mathrm{~mm}$; measurement range, $0-200 \mathrm{kPa}$ ) were buried in the topsoil at a depth of $100 \mathrm{~mm}$. They were placed under the center line of the track (Figure 6). Figure 7 shows the comparison between the simulated and measured ground pressures.

\section{Discussion}

The calculation error between the simulation and measure was smaller than $10 \mathrm{kPa}$, and the maximum error was smaller than $8 \%$. On this basis, the reasonability of the analytical model was verified and the results obtained by the simulation could be used in future research.

However, slight differences existed between the measured and simulated results and might be caused by the following reasons: first, the soil characteristics between the test and simulation differed; second, the measured results 


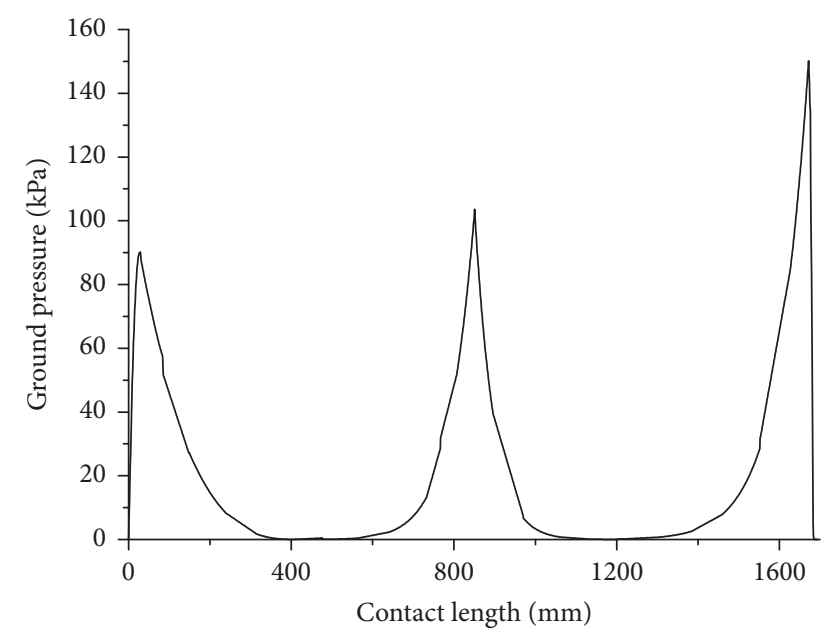

Figure 5: Ground pressure distribution under the track.

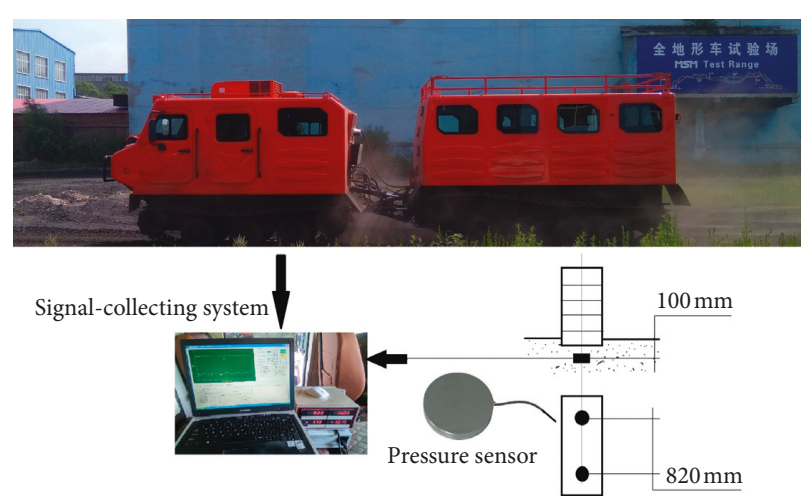

FIgURE 6: Test site of ground pressure.

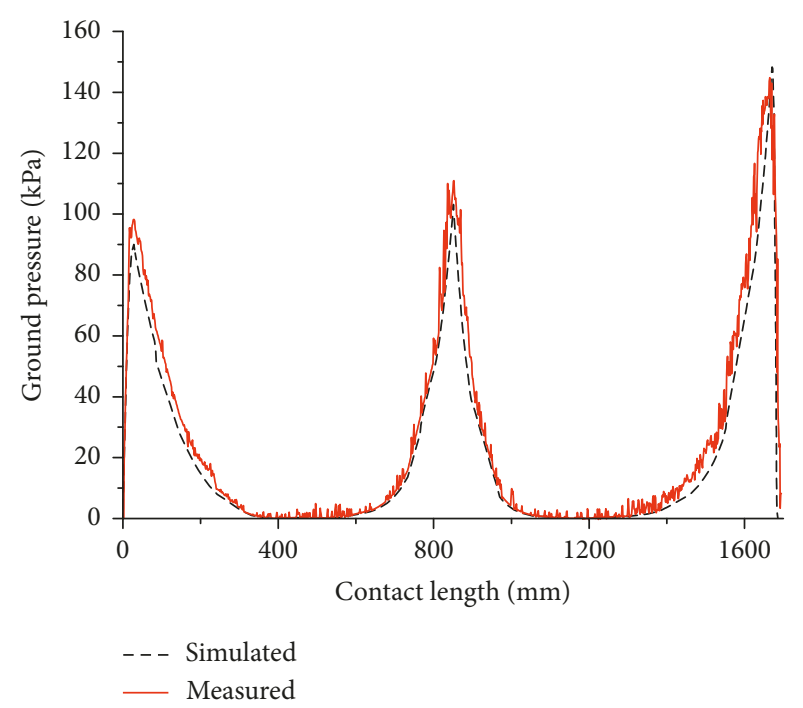

Figure 7: Simulated and measured results.

were almost larger than the simulated results, probably because the soil stiffness increased when the first track acted on the soil. Finally, the test process contained measurement errors that could not be avoided.

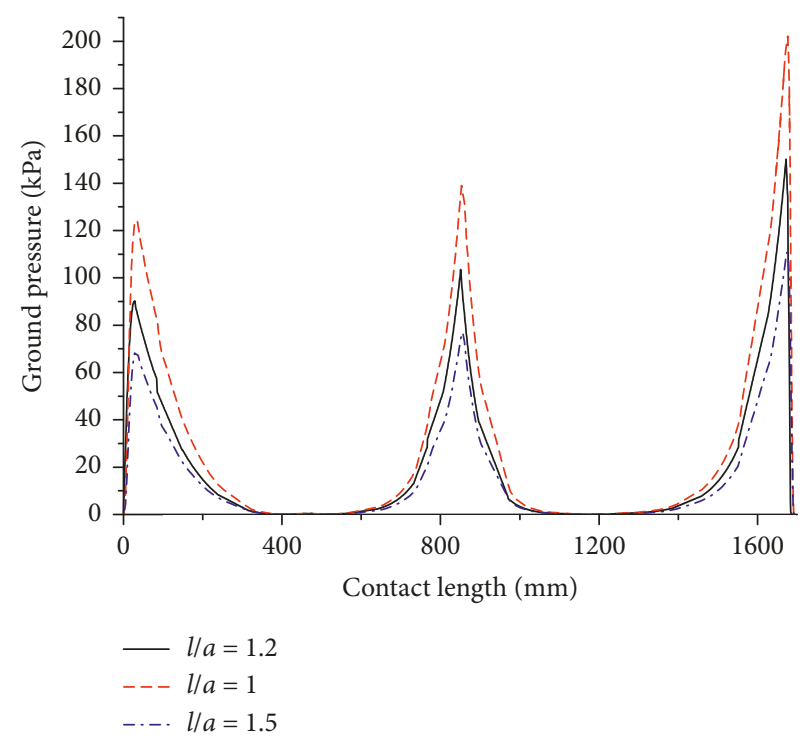

Figure 8: Comparison of different $l / a$ values.

TABle 2: Comparison of ground pressure under roadwheels.

\begin{tabular}{lccc}
\hline$l / a$ & Roadwheel 1 $(\mathrm{kPa})$ & Roadwheel 2 $(\mathrm{kPa})$ & Roadwheel 3 $(\mathrm{kPa})$ \\
\hline 1 & 125.97 & 140.07 & 203.62 \\
1.2 & 90.20 & 103.57 & 150.14 \\
1.5 & 69.11 & 77.04 & 109.30 \\
\hline
\end{tabular}

Figure 5 shows the ground pressure under the rigidflexible track along the longitudinal direction. The following conclusions can be drawn from the analytical results:

(i) The ground pressure is not uniform, and the ground pressure under the roadwheels is larger than that under the track between roadwheels, which is almost zero.

(ii) The nominal ground pressure of the tracked vehicle, which is obtained by dividing the vehicle weight by the soil-track contact areas, is $19.90 \mathrm{kPa}$. The ground pressures under the roadwheels, which are several times more than the nominal ground pressure, are $90.20,103.57$, and $150.14 \mathrm{kPa}$. Therefore, ground pressure is a better representation for mobility, tractive performance, and soil compaction than nominal ground pressure.

(iii) The influence of the lengths of the rigid grouser and flexible track on the ground pressure is analyzed. The original lengths of the flexible track and grouser are $90 \mathrm{~mm}$ and $74 \mathrm{~mm}$, respectively $(l=90 \mathrm{~mm}$, $a=74 \mathrm{~mm}$, and $l / a \approx 1.2)$. When increasing the length of the flexible track to $110 \mathrm{~mm}(/ / a \approx 1.5)$ and maintaining the total length of the track constant, the ground pressure increases. When increasing the length of the grouser to $90 \mathrm{~mm}(l / a \approx 1)$ and maintaining the total length of the track constant, the ground pressure decreases (Figure 8). Table 2 presents the comparison of ground pressure under the roadwheels. 


\section{Conclusion}

An analytical model for predicting ground pressure under a rigid-flexible tracked vehicle on soft ground was developed. The ground pressure distribution along the longitudinal direction was obtained, by considering the primary design parameters of the tracked vehicle and the soil characteristics.

The analytical model showed that the ground pressure under the roadwheels was considerably larger than that under the track between roadwheels. The maximum ground pressures under the roadwheels were 90.20, 103.57, and $150.14 \mathrm{kPa}$. The ground pressure was inversely proportional to $l / a$. When $l / a$ was large, the ground pressure was small and good mobility and slight soil compaction were obtained. However, when $l / a$ was small, the fatigue life was long.

The predicted ground pressure was relatively consistent with the values measured from the experiment. The error between the measured and simulated results was smaller than $8 \%$. The results supported the notion that the analytical model developed for predicting ground pressure was valid. This model can provide an effective prediction of ground pressure under a rigid-flexible tracked vehicle on soft ground and a significant reference for tracked vehicles.

\section{Data Availability}

The data used to support the findings of this study are included within the article.

\section{Conflicts of Interest}

The authors declare that they have no conflicts of interest.

\section{Acknowledgments}

This research was financially supported by the National Key Research and Development Program of China (no. 2016YFC0802703), which is gratefully acknowledged.

\section{References}

[1] M. G. Bekker, Introduction to Terrain Vehicle System, The Universtity of Mihigan Press, Ahn Arbor, MI, USA, 1969.

[2] L. J. Waldron, "The shear resistance of root-permeated homogeneous and stratified soill," Soil Science Society of America Journal, vol. 41, no. 5, pp. 843-849, 1977.

[3] J. Y. Wong, Theory of Ground Vehicles, John Wiley \& Sons, Hoboken, NJ, USA, 4th edition, 2008.

[4] T. Keller, A. Trautner, and J. Arvidsson, "Stress distribution and soil displacement under a rubber-tracked and a wheeled tractor during ploughing, both on-land and within furrows," Soil and Tillage Research, vol. 68, no. 1, pp. 39-47, 2002.

[5] J. Arvidsson, H. Westlin, T. Keller, and M. Gilbertsson, "Rubber track systems for conventional tractors-effects on soil compaction and traction," Soil and Tillage Research, vol. 117, no. 1, pp. 103-109, 2011.

[6] T. Keller and J. Arvidsson, "A model for prediction of vertical stress distribution near the soil surface below rubber-tracked undercarriage systems fitted on agricultural vehicles," Soil and Tillage Research, vol. 155, no. 1, pp. 116-123, 2016.

[7] Z. Zhao, X. Mu, and H. Guo, "Test and modeling on static ground pressure of rubber track conversion system,"
Transactions of the Chinese Society of Agricultural Engineering, vol. 34, no. 3, pp. 72-79, 2018.

[8] Z. Sun, L. Tang, and W. Wang, "Flexible track stress distribution considering slip subsidence," Transactions of the Chinese Society of Agricultural Engineering, vol. 48, no. 1, pp. 317-324, 2017.

[9] M. Garber and J. Y. Wong, "Prediction of ground pressure distribution under tracked vehicles-I. An analytical method for predicting ground pressure distribution," Journal of Terramechanics, vol. 18, no. 1, pp. 1-23, 1981.

[10] M. Garber and J. Y. Wong, "Prediction of ground pressure distribution under tracked vehicles-II. Effects of design parameters of the track-suspension system on ground pressure distribution," Journal of Terramechanics, vol. 18, no. 2, pp. 71-79, 1981.

[11] W. Y. Park, Y. C. Chang, and S. S. Lee, "Prediction of the tractive performance of a flexible tracked vehicle," Journal of Terramechanics, vol. 45, no. 4, pp. 13-23, 2008.

[12] J. Li, Q. Li, and J. Zhou, "Analysis of track-terrain interaction on soft soil," Acta Armamentarii, vol. 33, no. 12, pp. 14231429, 2012.

[13] C. Yang, L. Cai, Z. Liu, Y. Tian, and C. Zhang, "A calculation method of track shoe thrust on soft ground for splayed grouser," Journal of Terramechanics, vol. 65, no. 1, pp. 38-48, 2016.

[14] J. Y. Wong and W. Huang, "An investigation into the effects of initial track tension on soft ground mobility of tracked vehicles using an advanced computer simulation model," Proceedings of the Institution of Mechanical Engineers, Part D: Journal of Automobile Engineering, vol. 220, no. 6, pp. 695$711,2006$.

[15] J. Y. Wong, C. Senatore, P. Jayakumar, and K. Iagnemma, "Predicting mobility performance of a small, lightweight track system using the computer-aided method NTVPM," Journal of Terramechanics, vol. 61, no. 1, pp. 23-32, 2015.

[16] M. Meywerk, T. Fortmüller, and B. Fuhr, "Real-time model for simulating a tracked vehicle on deformable soils," Advances in Mechanical Engineering, vol. 8, no. 5, pp. 1-14, 2016.

[17] W. Liu, K. Cheng, and J. Wang, "Failure analysis of the rubber track of a tracked transporter," Advances in Mechanical Engineering, vol. 10, no. 7, pp. 1-8, 2018. 


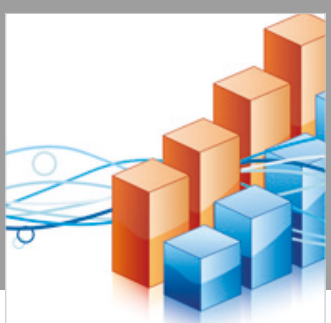

Advances in

Operations Research

\section{-n-m}
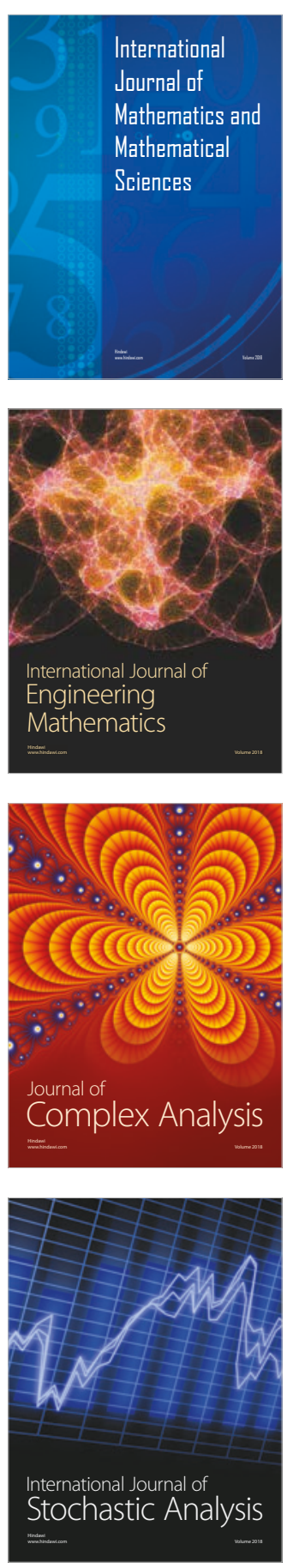
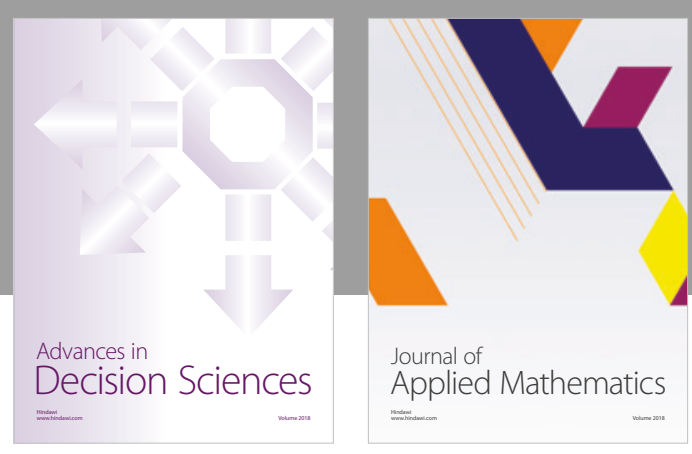

Journal of

Applied Mathematics
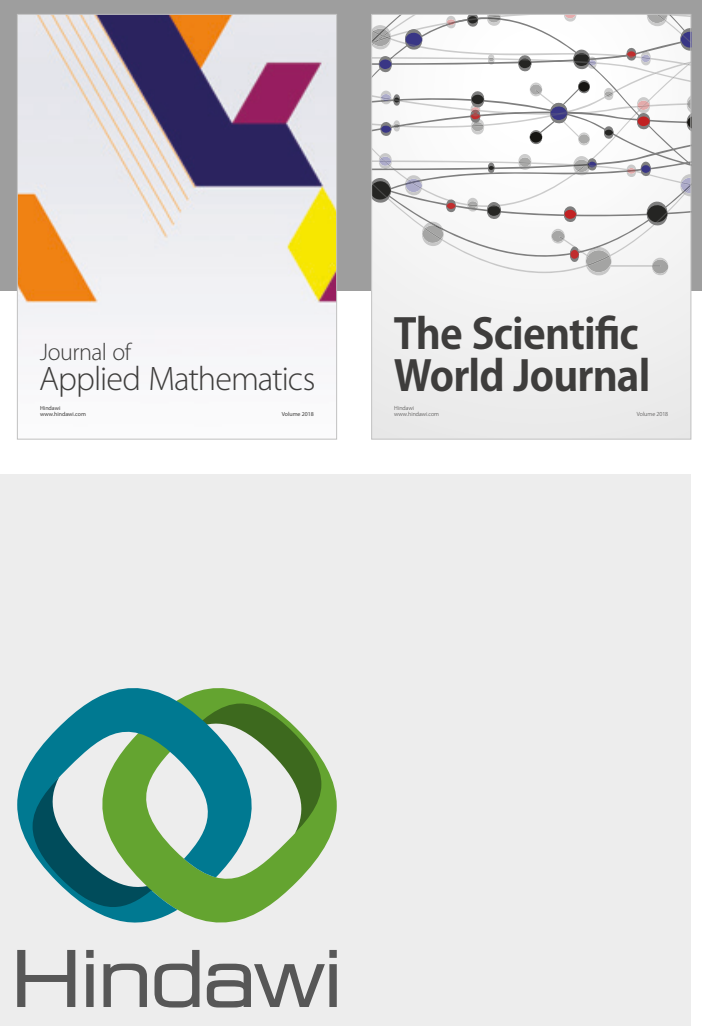

Submit your manuscripts at

www.hindawi.com

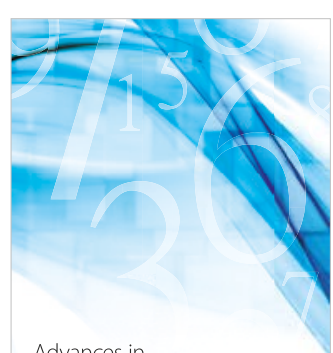

Advances in
Numerical Analysis
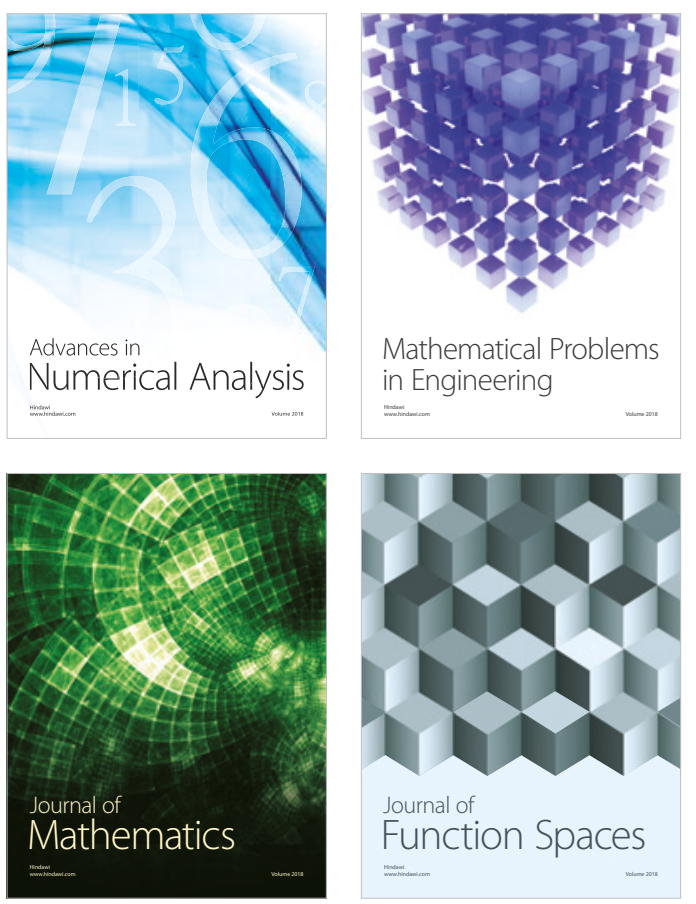

Mathematical Problems in Engineering

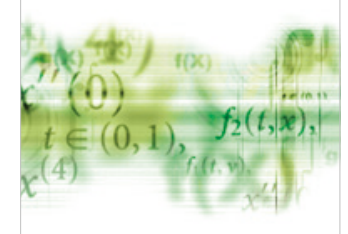

International Journal of

Differential Equations

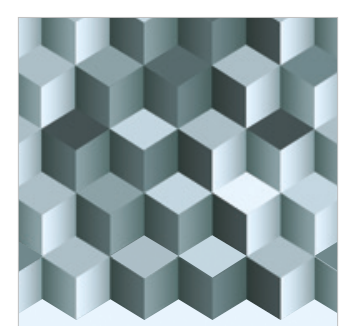

Journal of

Function Spaces
The Scientific

World Journal

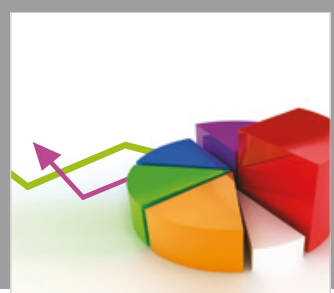

Journal of

Probability and Statistics
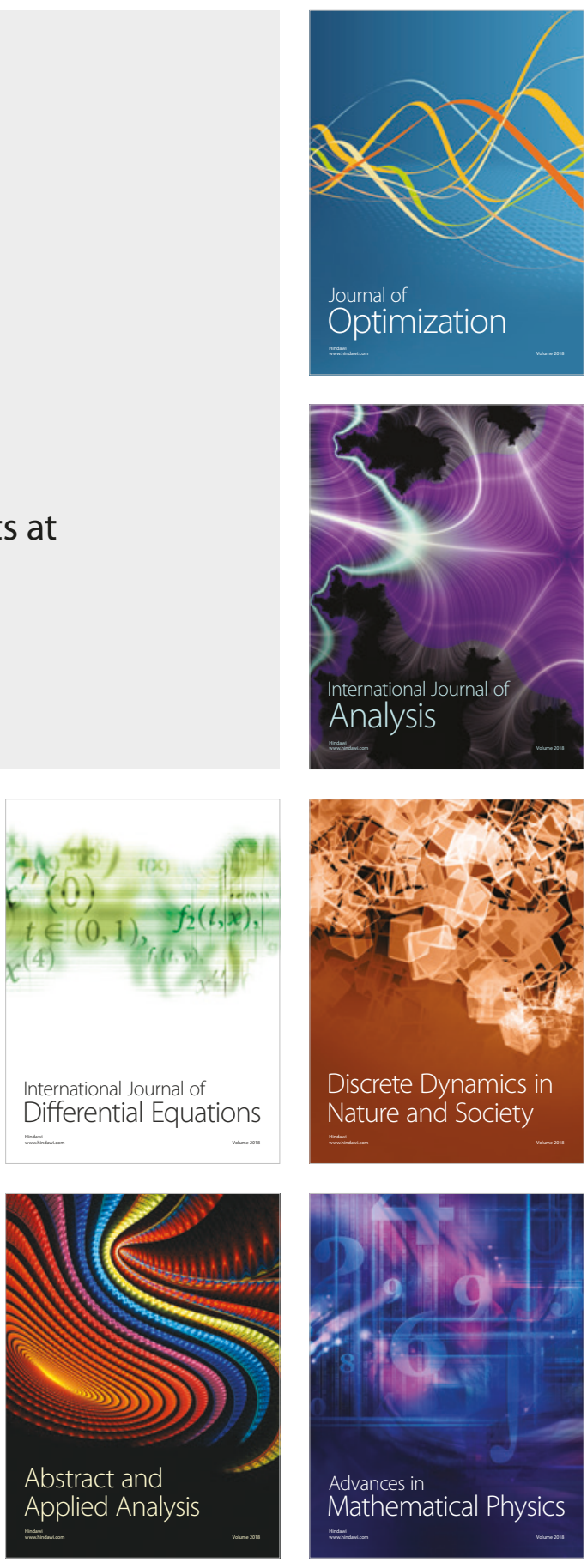